Revista Iberoamericana. Vol. LXV, Núm. 187, Abril-Junio 1999; 293-304

\title{
LA HOMOSEXUALIDAD CÓSMICA MEXICANA: ESPEJOS DE DIFERENCIA RACIAL EN XAVIER VILLAURRUTIA
}

\author{
POR
}

\author{
ROBERT IRWIN \\ New York University
}

\begin{abstract}
Andrés era pobre y Rafael era rico.
Andrés era poeta y Rafael era filósofo.

Andrés era rubio y Rafael era moreno.

¿Sorprenderá alguien que se hayan amado?
\end{abstract}

Amado Nervo, El donador de almas

En muchas ocasiones los pensadores mexicanos se han contemplado ante el espejo en un ritual de descubrir lo mexicano, lo verdaderamente mexicano detrás de las máscaras, el alma desnuda, rajada, pelada. Desde su jaula de la melancolía o su laberinto de la soledad, las figuras más soberbias de la inteligencia mexicana han esbozado, codificado y desconstruido las esencias centrales de su patria querida. Se han expuesto desde innumerables ángulos, tanto el perfil del hombre y la cultura como el de la mujer y la barbarie en México. Y si no se ha presentado nítidamente lo auténticamente mexicano, pues, por lo menos tenemos gran variedad de pistas para guiarnos hacia lo mero mero (Véase, por ejemplo, a Ramos, El laberinto de soledad de Paz, Bartra).

Sin embargo, como se piensa que el mexicano es una figura melancólica, introvertida, impenetrable y solitaria, es difícil entender cómo convive con la mexicana (o con otro mexicano), sobre todo en cuanto a las relaciones sexuales. De hecho, a pesar de que haya habido muchos intentos de definir un deseo sexual mexicano, ninguno ha sido completo. Lo que me propongo hacer es unir algunos de los tropos más conocidos de la sexualidad mexicana para mostrar que aun juntados hay vacíos, como indicarán algunos textos de Xavier Villaurrutia. Este poeta/crítico/dramaturgo mexicano que se sirve de la inversión como método poético (Manuel Maples Arce, Antología de la poesía mexicana moderna, citado en Sheridan, Los contemporáneos 133) nos ha dejado un pequeño cuerpo de escrituras que desmienten las versiones heterosexistas del deseo mexicano mientras desmantelan los modelos rígidos y falsos del deseo homosexual mexicano, para construir una sexualidad mexicana más fluida, borrosa y elusiva de lo que han imaginado los que andan en busca de lo mexicano.

El deseo heterosexual en México siempre ha sido problemático. ¿Qué hacen los conocidos hombres necios con las hijas de la Malinche? Para Octavio Paz, parece que lo mexicano se define a través de una especie muy específica de deseo heterosexual: un deseo activo, agresivo, hasta sádico y destructivo por parte del hombre blanco por una mujer 
abnegada, pasiva, seductora - pero desamparada e india. El mexicano, esencialmente mestizo, es el producto de la violación de la indígena mesoamericana por el conquistador español. Esta visión simbólica de la conversión primero del Anahuac en la Nueva España, después en el México independientey, luego, en el postrevolucionario país mestizo del siglo veinte por medio de un mestizaje gradual - un mestizaje racial y cultural, toma en cuenta más que el mero género. Paz reconoce la importancia del poder y la raza y las diferencias que van más allá del género y la biología vulgar. En México el poderoso viola a la débil; la pobre seduce al rico; el rubio corteja a la morena; y hay una implicada inestabilidad intrínseca en las jerarquías sociales (El laberinto 64, 68-73, 77-78, etc.). Aunque los resultados pueden ser desastrosos como hemos visto en los casos de La Quijotita, La Rumba, Santa, la Mujer del Puerto' y de tantas mexicanas (y mexicanos), y no sólo con la pobre Malintzin, el tropo claramente tiene una gran importancia simbólica, y los seguidores de Paz son muchos. ${ }^{2}$

Lo que no explica el modelo del mestizaje de Paz es la posibilidad de variación de formas de deseo. Por ejemplo, en su modelo, los hombres morenos simplemente no desean, y el ideal de la mujer blanca y rubia que aparece tanto en la literatura mexicana no se explica. Tampoco se puede entender la noción de la voluntad de parte de la mujer mexicana (como la Rumba, Santa, la Adelita, la Pintada, Claudia Nervo, entre otras). ${ }^{3}$

José Vasconcelos tiene más perspicacia en las cuestiones de la raza — "por mi raza hablar el espíritu", comentó un día histórico. Nos desentenderemos del hecho que Vasconcelos abandonó su raza como una iguana cambia de piel y se convirtió de mestizo en criollo una década después de la publicación de su obra maestra La raza cósmica. ${ }^{4}$ Tampoco estamos completamente conformes con su elección de la figura tolteca de Quetzalcóatl, civilizador del México bárbaro, como símbolo de su persona pública. Sin embargo, su visión del proceso de mestizaje es más completa que la de Paz.

Según el Maestro de la Juventud americana, el mestizaje es un proceso de selección natural. Su visión utópica racial no necesita la eugenesia; para él, "la raza definitiva, la raza síntesis o raza integral" (30) se realiza como función de la estética universal. "Las leyes de la emoción, la belleza y la alegría regirán la elección de parejas, con un resultado infinitamente superior al de esa eugénica fundada en la razón científica" (40). Los guapos (blancos, negros, indios, mogoles) procrearán con las guapas.

El mundo vasconceliano no es sencillo. El mestizaje es parte de un desarrollo histórico muy largo en el cual las diferentes razas mundiales han subido, cada una en su turno, a una

\footnotetext{
' Fernández de Lizardi, La Quijotita y su prima; Campo, La Rumba; Gamboa, Santa; La mujer del puerto (película).

${ }^{2}$ El tropo de la violación de un México indígena femenino por una España conquistadora viril llegó a ser un lugar común en los muchos psicoanálisis del mexicano en los cincuentas y sesentas (Ramírez 61-62, Aramoni 277-80; y más recientemente Goldwert 1-2); se encuentra también en el pensamiento chicano más reciente (Paredes 65, Mirandé 34-49).

${ }^{3}$ La Pintada es una soldadera atrevida en Azuela, Los de abajo; Claudia Nervo es la protagonista de Fuentes, Zona sagrada.

${ }^{4}$ La raza cósmica, de hecho, no se preocupa específicamente por lo mexicano, sino por lo americano. No obstante, su interés en lo mestizo, característica ejemplar de lo mexicano, indica su pertinencia a nuestra discusión. Nos presenta su identidad criolla en su "novela autobiográfica", Ulises criollo.
} 
posición dominadora y luego han cedido el poder a razas sucesivas. La raza blanca, la actualmente hegemónica, se ha dispersado por todo el mundo posibilitando la síntesis de las razas, la raza cósmica. La quinta raza — como el quinto sol azteca- representa la última etapa de la evolución racial universal. Todo se cumplirá cuando ya no haya razas puras y cuando ya no haya gente fea.

Aunque la teoría de Vasconcelos es claramente una explicación del mestizaje que obviamente depende de relaciones fecundas heterosexuales, no hay indicaciones de que sus reglas se limiten a lo heterosexual. Si el deseo es función de la belleza, y si existen homosexuales (y Vasconcelos claramente reconoce su existencia en otros momentos), ${ }^{5}$ ¿por qué no se aplica la teoría de la raza cósmica al deseo homosexual? ¿No es posible que el deseo mexicano homosexual también opere en un eje estético racial?

Pues, Paz tiene otra opinión. Para él, la homosexualidad mexicana es una especie de parodia involuntaria de la heterosexualidad. El hombre homosexual asume el papel de mujer y tiene relaciones con hombres verdaderos, no homosexuales, a pesar de los actos homosexuales que realizan. En términos freudianos, la homosexualidad mexicana es una función del fin sexual, el acto de penetración anal, y no del objeto sexual, la atracción por un hombre (El laberinto 35). La homosexualidad $-\mathrm{y}$ hay que notar que para Paz la homosexualidad mexicana es una institución puramente masculina - no tiene que ver con la belleza que es motor del sistema de relaciones heterosexuales en México (según Vasconcelos). Ni la estética ni la diferencia racial figuran en el modelo de Paz. El homosexual mexicano, entonces, sigue el modelo heterosexual de la violación según Paz. Imita a la mujer mexicana, seductora pero esencialmente pasiva. Emula a la Malinche con una sola diferencia: asume todo lo que implica su género, pero ignora su raza.

Por supuesto el modelo de Paz es poco desarrollado - y, de hecho, no fue su intención definir cuidadosamente la homosexualidad mexicana; meramente se refirió a ella para esbozar mejor su visión del machismo-y él mismo reconoció algunas contradicciones en su pensamiento sobre el asunto. Por ejemplo, Paz encuentra la contaminación del deseo homosexual en los espacios puramente machos; en otras palabras, halla la homosexualidad en los hombres heterosexuales ("No sería difícil percibir también ciertas inclinaciones homosexuales [en el macho mexicano], como el uso y abuso de la pistola, símbolo fálico portador de la muerte y no de la vida, el gusto por las cofradías cerradamente masculinas, etc."; El laberinto 74). Pero la importancia de este modelo es indudable dado que la mayoría de las investigaciones sociológicas sobre la sexualidad masculina mexicana lo han empleado como punto de partida (Véase, por ejemplo, a Carrier y a Murray). El tropo singular de la homosexualidad mexicana bosquejado por Pazjamás ha sido interrogado seriamente a pesar de sus obvias fallas de reducción, autocontradicción y dependencia en elementos simbólicos para definir los comportamientos materiales.

No hay espacio aquí para desconstruir rigurosamente la homosexualidad mexicana según Paz (ni tampoco la heterosexualidad según Vasconcelos). Lo único que intento hacer

\footnotetext{
${ }^{5}$ En El desastre, el tercer volumen de su Ulises criollo, "La Providencia me ha librado hasta hoy de dos pecados únicamente: la blasfemia y la sodomía" (186); luego, en La flama, interpreta los escritos personales de su amante suicida, "Valeria" (Antonieta Rivas Mercado), echándoles la culpa de su muerte a sus amigos homosexuales (118-19, 122-23, 215).
} 
es investigar un poco cómo cambian estas visiones de la homosexualidad mexicana cuando abarcan cuestiones de raza. Para hacerlo, volvemos a la escritura de Xavier Villaurrutia, una de las primeras figuras literarias mexicanas abiertamente homosexuales, y uno de los pocos escritores homosexuales mexicanos que se ocupan de cuestiones raciales.

A pesar de frecuentes acusaciones de extranjerizante o afrancesado, Octavio Paz lo describe como "obstinado, ferviente patriota" y "mexicanista" (Xavier Villaurrutia 27). No participaba en la política nacionalista postrevolucionaria, una política que Jorge Cuesta, colega de Villaurrutia, criticaba, sobre todo en cuanto a su insistencia en una literatura nacional, por ser "una idea europea que estamos empeñados en copiar" (107). Sigue Cuesta, en términos con los cuales Villaurrutia hubiera estado indudablemente de acuerdo: "La idea más infecunda en el arte y la literatura mexicanos ha sido la idea nacional. Las obras nacionalistas no han logrado otra cosa que imitar servilmente a los nacionalismos de Europa" (109). Villaurrutia era universalista y mexicanista, y como indica Paz, hay vínculos entre sus poemas y obras literarias europeas (Gide, Cocteau, Rilke, Chirico, etc.), pero también lazos estrechos con obras mexicanas (Sor Juana, López Velarde, Pellicer, etc.).

Extranjerizante o no, el hecho que Villaurrutia es uno de los primeros homosexuales conocidos en las letras mexicanas le da un lugar singular en la historia literaria mexicana. Junto con algunos textos de Salvador Novo, las obras homoeróticas de Villaurrutia son fundadoras; establecen el tema del deseo homosexual en el canon de la literatura mexicana. Aunque no podemos juzgar si la sexualidad villaurrutiana es representativa de los homosexuales mexicanos en general o típica de los de su generación o clase social, él, de hecho, ofrece algunas de las pocas pistas para entender algo de la homosexualidad en México en la primera parte del siglo. Octavio Paz no se representa como homosexual, y presenta una homosexualidad mexicana por medio de una discusión sobre la heterosexualidad masculina ( $\mathrm{y}$ acaso por eso encuentre una homosexualidad modelada en los patrones de la heterosexualidad); Villaurrutia, en cambio, nos presenta directamente un deseo homosexual y establece, sobre todo en su Nostalgia de la muerte [1938], sus paradigmas en la historia literaria mexicana, haciendo que su obra y su vida sean puntos de interés para los interesados en entender la historia de la homosexualidad mexicana. ${ }^{6}$

La raza negra se presenta a veces en México como la raza esclavizada y subyugada por los estadounidenses. ${ }^{7}$ Las pocas veces que aparecen los negros en la literatura mexicana como protagonistas nacionales, siempre tienen papeles marginales. Por ejemplo, hay el salteador, el Aguilucho, amigo del Periquillo Sarniento, o los negritos que aparecen en varios villancicos de Sor Juana. ${ }^{8}$ En otras ocasiones asumen papeles más centrales, pero en

\footnotetext{
"El mejor intento de delinear tal historia es el de Monsiváis, "Ortodoxia" 200-01.

${ }^{7}$ Véase, por ejemplo a Vasconcelos, La raza 28; Castellanos, "Discriminación en los Estados Unidos y en Chiapas".

${ }^{8}$ Un ejemplo de Villancico VIII del tercer nocturno de los villancicos de la Concepción de 1676: “¿Quién es? - Un Negliyo. - ¡Vaya, vaya fuera, que en Fiesta de luces, toda de purezas, no es bien se permita haya cosa negra! -Aunque Neglo, blanco somo, lela, lela, que il alma rivota blanca sá, no prieta ..." (Sor Juana 217).
} 
obras marginales como La negra Angustias de Francisco Rojas González." Tal vez se encuentren más fácilmente no en la alta cultura de la literatura nacional sino en la leyenda, la literatura hablada de la cultura popular. Por ejemplo, tenemos el ejemplo del legendario Negrito Poeta del siglo XVIII. ${ }^{10}$ También era muy bien conocida en el siglo diecinueve la leyenda (muy probablemente repetida desde el siglo anterior o antes) de la Mulata de Córdoba.

"La fantástica leyenda de la Mulata de Córdoba ha vivido en la tradición del pueblo y ha sido trasmitida hasta nosotros en miles de ediciones, hechas ya al calor del hogar por la abuelita para entretener a los nietos, o por la pilmama para dormir a los niños; y por el cansado caminante para acortar las noches, o por el soldado para amenizar las veladas del campamento" (González Obregón 326). Vivió en Córdoba, ciudad de Veracruz, una mujer misteriosa, una joven sin padres, que aparentemente nunca envejecía. Según las malas lenguas era bruja y había hecho pacto con el diablo. Por su belleza, los hombres se enamoraban de ella, pero rechazaba a todos, y de ahí nació la creencia de que el único dueño de sus encantos era el diablo. Sin embargo, se comportaba como mujer religiosa, generosa y caritativa. Ayudaba a la gente: a las mujeres que buscaban maridos, a los hombres sin empleo, a los ambiciosos y desafortunados de todo tipo - y producía resultados tal vez milagrosos. Es, obviamente, el origen de la expresión empleada para contestar una demanda irrealizable: "¡No soy la Mulata de Córdoba!"

Por razones no muy claras la trajo de Córdoba a la ciudad de México el Santo Oficio - quizás porque la iglesia codiciaba su putativa fortuna, o porque un pretendiente rechazado se vengó de ella denunciándola. Una vez allí, encarcelada, vino un monje para interrogarla y encontró dibujado en la pared de su celda un navío. Entonces, ella le preguntó con tono irónico: “¿Qué le falta a ese navío?” y él contestó que únicamente le faltaba que anduviera. "Pues", desafió ella, "él andará". Y con esto, saltó al navío que pronto desapareció, con ella a bordo. Ella nunca más fue vista en México, pero se dice que llegó a Manila (González Obregón 325-30).

La leyenda vive todavía, no sólo en la cultura popular sino también en la alta cultura del Palacio de Bellas Artes donde se presentó por primera vez la obra escrita para cine, $L a$ Mulata de Córdoba de Xavier Villaurrutia en 1939 (Obras 191-226), y donde otra versión todavía forma parte del repertorio de la Compañía Nacional de Ópera para la cual Villaurrutia escribió el libreto (Obras 227-249).

El escenario cinematográfico presenta una versión modernizada que toma lugar en 1910. Se inicia con un gesto gideano (y no se deben menospreciar las implicaciones subversivas del autor de Corydon en México; Sheridan, Contemporáneos 92 n.29): el regreso del hijo pródigo que aquí se llama Pedro. En esta historia, Pedro, su hermano y hasta su padre son amantes de la mulata, Sara. Sara, como bastarda y mulata no es pareja aceptable para Pedro (y menos para su padre, don Juan). Sara atrae a los hombres de las familias que la humillan para vengarse. Sigue Sara con Pedro aun después de que éste se casa con otra

\footnotetext{
"Monsiváis desecha a Rojas González del canon literario mexicano en medio párrafo sin siquiera citar La negra Angustias ("Notas" 1458).

${ }^{10}$ El Negrito Poeta era un personaje mítico, supuesto autor de epigramas, tales como: “¡Pobre de ti que te quejas a mí, para tu remedio! que te partan por en medio y tendrás 'dos medias viejas '”'(Campos 94).
} 
vecina, Emilia. Cuando es claro que ha destruido el matrimonio, las dos familias pelean entre sí y el padre de Emilia (que también es conocido como el tío de Sara) cae muerto por un balazo. No obstante resulta que el asesino no es Pedro, ni don Juan, sino un criado (negro) de Sara, mandado por ella para matarlo. Luego, los demás deciden aplicar la justicia cruda, pero al llegar a la casa de Sara, la encuentran vacía. Termina la historia así: "A medida que Pedro y don Juan abren, una a una, las puertas de las habitaciones de la enorme casa, se oirá, en cada alcoba que encontrarán desierta, resonar, no sabemos si en la realidad misma o sólo en la mente de Pedro y don Juan, una risa vibrante, cruel y desesperada, irónica, malvada: la risa diabólica de la Mulata de Córdoba" (226).

La segunda versión, la ópera sigue más la leyenda tradicional. Sucede en vísperas de la guerra de independencia. La mulata, que ahora se llama Soledad, es guapa, amada por los hombres a quienes desdeña. Admite ser bruja y tener pacto con Satanás. Cuando un hombre a quien había rechazado trata de matarla e interviene otro enamorado, éste cae muerto y el primero, el asesino, le echa la culpa a la mulata que termina encarcelada por la Inquisición. En la prisión, reaparece el muerto vestido de fraile. Él llega con tiza y trata de convencerla de escribir (si no acepta confesarse verbalmente) el nombre de su "padre" (su amante putativo, Satanás). En vez de obedecerlo, Soledad dibuja una embarcación. "Mientras los Inquisidores y el Coro, sorprendidos, inefables, contemplan la obra de arte inesperada, Fray Anselmo se ha esfumado; la Mulata de Córdoba sube al bajel y, navegando, desaparece" (249).

En las dos versiones villaurrutianas, la figura de la heroína es sexualmente subversiva; manipula a los hombres, ejerciendo cierto poder sobre ellos. Sexualmente libre, también su vida íntima es un enigma; sus nexos ilícitos son privados y desconocidos. La raza se asocia a la promiscuidad (la mulata y su madre), la criminalidad (la mulata y su criado), el pecado y la subversión social en general. La mulata no se casa, no se somete a los hombres; de hecho, utiliza su sexualidad para combatir las instituciones culturales de género y sexualidad femenina.

Interesantemente, en los dos casos, ella misma es inocente de los asesinatos. En el primer caso acusan a su criado y luego la juzgan culpable a ella sin investigación. En la ópera, su inocencia es aun más clara. Son los celos o el orgullo lastimado del asesino que provocan el crimen. Culpan a la que se propone como víctima. En ninguno de los dos casos se preocupa la gente por los verdaderos responsables. Por eso, y por el hecho de que la justicia administrada o por los ciudadanos vidos (y vengativos), o por la malvada Inquisición, el personaje de la Mulata de Córdoba es una heroína trágica, víctima de la injusticia. Y cuando se escapa ella al final, dejando atontados a sus enemigos, goza de las simpatías del lector que se identifica con ella, sobre todo un lector homosexual como era el mismo escritor, disidente sexual, blanco de la hostilidad de una sociedad que desaprueba, critica y criminaliza su sexualidad.

Desafortunadamente los homosexuales mexicanos no pudieron escapar tan fácilmente a Manila cuando los perseguían. Si los ataques retóricos (de ser afeminados, inmorales, invertidos, maricones y hermafroditas) no siempre tenían consecuencias palpables, algunas veces sí los afectaron materialmente (Sheridan, Contemporáneos 132-133, 255-260; Monsiváis, Amor perdido 273-277; Paz, Xavier Villaurrutia 24-25). Por ejemplo, en una de las cazas de brujas (la de 1932), despidieron a varios intelectuales homosexuales (o mejor 
dicho, intelectuales acusados de ser homosexuales), incluyendo a Villaurrutia, de sus puestos burocráticos.

La figura de la Mulata de Córdoba fue un vehículo para expresar una sexualidad que Villaurrutia casi nunca se atrevía a enfrentar directamente en su arte. Sin embargo, tal uso alegórico de la raza no nos ayuda a completar los modelos de Paz y Vasconcelos porque en estas obras, el deseo sigue siendo heterosexual. No nos clarifica cómo se entrelazan la raza y la homosexualidad mexicana. Hay que buscar en otros lugares en Villaurrutia para que se elucide un poco el asunto.

El poema más audaz, más erótico de Villaurrutia - su poema "con asunto", como comentó una vez irónicamente (citado en Sheridan, "Villaurrutia habla" 222) - es su "Nocturno de los ángeles" (o de Los Ángeles). Fue escrito en Los Ángeles durante su único viaje al extranjero en 1936 y se trata de una ciudad "maravillosa de noche". Según contaba en una carta a Salvador Novo, "Ni en New York fluye, como aquí, el deseo y la satisfacción del deseo" (Cartas 75). En el poema bajan los seres celestiales, los ángeles bellos, para formar "imprevistas parejas" con "los mortales". Sus relaciones se realizan en hoteles y la danza erótica de las calles nocturnas se repite, juntando los ángeles con los mortales quienes "como los Gemelos que por vez primera en la vida se [miran] de frente a los ojos, se [abrazan] para siempre".

Se supone que los lectores de Villaurrutia se tienen que identificar con los mortales, y que los ángeles son los seres deseados por aquellos. A primera vista, este deseo que forma una constelación en figura de "un ardiente sexo" parece ser narcisista en el sentido más estrecho de la palabra - los ángeles son los gemelos de los mortales-y aunque los ángeles (que se llaman "Dick o John, o Marvin o Louis") se pueden identificar como estadounidenses, la cuestión de la diferencia racial nunca se plantea en el poema - hasta que consideramos el manuscrito encontrado hace algunos años a la muerte de Carlos Pellicer, un manuscrito con dibujos bosquejados por Villaurrutia, dibujos evocadores de Le livre blanc de Jean Cocteau a pesar de no ser tan explícitos, dibujos de marineros rubios, abrazándose y besándose, como los gemelos unidos del texto. ${ }^{11}$

La fantasía es complicada si tratamos de ubicar a Villaurrutia o a su lector mexicano en la escena. ¿Es una fantasía voyeurista de espiar a los juegos eróticos de los marineros homosexuales en los Estados Unidos en la cual se queda pasivo y alejado el observador mexicano? ¿O es un caso del narcisismo en que el mexicano se identifica con el rubio no porque él también sea rubio, sino porque quiere ser rubio? Como señala Freud, el narcisismo toma varias formas. El narcisista puede amar a una persona que se parece al que es, o al que es en un pasado idealizado, o al que formaba parte de él en ese pasado idealizado, o al que quiere ser (90). ¿Quería Villaurrutia identificarse con los rubios de los Estados Unidos, país rico, grande y con cierto nivel de libertad sexual?

Otra posibilidad sería relacionar el poema con la obra de André Gide. Aunque los dibujos nos recuerden a los de Cocteau, fue Gide quien ejercía una influencia (una influencia "moral" como afirmó una vez Villaurrutia) sobre el mexicano (Issorel 115). Su Corydon ya tenía su notoriedad en México en los treintas y Villaurrutia disfrutabajugar con su imagen pública al mencionar o referirse a ciertas figuras controvertidas ( $\mathrm{y}$ homosexuales) como

$"$ En Nocturno de los ángeles aparece un facsímil del manuscrito original. 
Whitman, Wilde y Gide. Sin embargo, ni el erotismo interracial y el turismo sexual que se encuentran en $L$ 'immoraliste y Si le grain ne meurt, ni la economía de deseo y la pederastia institucional que se fomentan en Corydon, explican el narcisismo villaurrutiano, su imagen inconfundible de los gemelos, de los ángeles fundiéndose con sus amantes mortales.

Ninguna de estas tres explicaciones satisface. En ningún otro momento tiene la poesía erótica de Villaurrutia elementos de voyeurismo. Tampoco envidiaba el poeta la libertad sexual de los Estados Unidos; de hecho, no hay indicaciones de que estuviera descontento con la vida subterránea homosexual de la ciudad de México. Además, la influencia moral que sentía de Gide venía no tanto de sus gustos particulares como de su "orgullo gay", o sea, su valor al expresar sus inclinaciones y pasiones sin preocuparse demasiado de su reputación. Para entender como figuraba la diferencia racial en el erotismo villaurrutiano, hay que ver un poema más.

"North Carolina Blues" (Obras 65-66), el poema que Villaurrutia dedicó a Langston Hughes, es muy poco estudiado. Tampoco sabemos mucho de los vínculos que existían entre los dos escritores. Hughes, cuyo padre vivió la mayor parte de su vida en México, viajó a México varias veces; también es posible que Hughes y Villaurrutia se hayan conocido en 1935 o 1936 cuando éste estuvo en los Estados Unidos. No obstante, no es claro si Villaurrutia conocía personalmente a Hughes o si simplemente lo admiraba. De todos modos, el hecho de la dedicatoria a Hughes no significa una influencia. "North Carolina Blues", a pesar de su título en inglés y su asunto - lo negro en un contexto estadounidense, más bien es representativo de dos estilos típicos de la obra poética de Villaurrutia.

Primero, se encuentran los juegos lingüísticos vanguardistas que en este caso no se tratan de lo blanco ("¿Qué nombre dar a la blancura sobre lo blanco?" escribe en "Cementerio en la nieve", Obras 64) sino de lo negro: “¿Cómo decir que la cara de un negro se ensombrece?", y luego, "Habla un negro: - Nadie me entendería si dijera que hay sombras blancas en pleno día". En un caso raro, el jugueteo de Villaurrutia tiene implicaciones casi políticas: "En diversas salas de espera aguardan la misma muerte los pasajeros de color y los blancos, de primera". Luego aparece la familiar imagen de un cuerpo fragmentario: "Una mano sin cuerpo escribe y borra negros nombres en la pizarra". Así que el cuerpo negro figura al nivel simbólico en el lenguaje poético villaurrutiano, con sus sombras, lo nocturno ("En North Carolina el aire nocturno es de piel humana"), la muerte, misteriosa pero íntima, inquietante pero sensual.

Este erotismo es el segundo elemento familiar que se halla en "North Carolina Blues". Los cuerpos negros del poema son abstractos, metaforizados ("Meciendo el tronco vertical, desde las plantas de los pies hasta las palmas de las manos el hombre es árbol otra vez"), tratados con ironía en ciertos momentos, pero muy erotizados en otros. La primera estrofa contiene un gesto bastante inusitado en él: el poeta participa activamente de la acción erótica del poema. ${ }^{12}$ Hablando del aire nocturno (hecho "de piel humana"), escribe: "Cuando lo acaricio me deja, de pronto, en los dedos, el sudor de una gota de agua". Entretejido en su

\footnotetext{
${ }^{12}$ Más típica es su estrategia en "Nocturno de la estatua" (Obras 46-47) de evadir la necesidad de construir a personas identificables empleando verbos en forma infinitiva, sin sujetos ("Soñar, soñar la noche, la calle, la escalera/ y el grito de la estatua desdoblando la esquina./ Correr hacia la estatua y encontrar sólo el grito,/ querer tocar el grito y sólo hallar el eco, [...]").
} 
escena despoblada nocturna (lugar común en Nostalgia de la muerte), se encuentra la imagen palpable del poeta acariciando la piel negra, sudorosa.

En otro momento se repite una imagen de "Nocturno de los ángeles". Esta vez los seres erotizados se confunden con la noche misma y se quedan invisibles, pero la escena tiene claras implicaciones de ligues callejeros, relaciones ilícitas, pasiones ardientes.

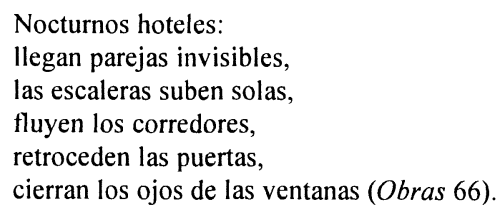

La invisibilidad de los protagonistas es otro juego con lo negro y lo nocturno, pero también leída junto con los ojos cerrados de las ventanas ${ }^{13}$ indica que son relaciones que no se deben ver, que no se pueden describir, que tienen que quedar ensombrecidas.

La última estrofa también nos recuerda a "Nocturno de los ángeles":

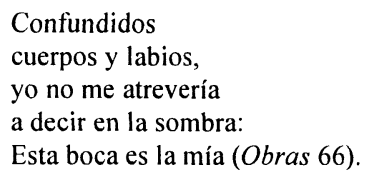

Otra vez los cuerpos se confunden, los labios se juntan en una manera ahora absoluta. La identidad del poeta, y significativamente su raza, se pierden. En el acto sensual el poeta se funde con su amante.

Lo interesante es que el sexo como fundidor de identidades sólo se presenta así en estos dos poemas, los únicos poemas villaurrutianos marcados por la diferencia racial. Tomando en cuenta el hecho de que en la mayoría de los poemas eróticos de Villaurrutia, ni siquiera aparecen cuerpos identificables - más bien hay sombras, voces sueltas, fragmentos corporales, la presencia de cuerpos blancos y negros indica que la diferencia racial tiene un valor evidente en estos dos poemas.

El narcisismo villaurrutiano, entonces, no sigue un simple lenguaje freudiano de buscar una versión (presente, pasada o futura) de sí mismo en el otro. Aquí, es el otro, no el mismo, el que domina. En otro momento, Villaurrutia pinta una imagen singular: "el juego angustioso de un espejo frente a otro" ("Nocturno en que nada se oye", Obras 47). Como espejo del amante, el poeta se pierde en el otro, fundiéndose con él. Si el protagonista poético no llega a ser el otro, el otro tampoco se pierde en aquel; lo que pasa es que se entregan hasta el punto en que la diferencia entre los dos se evapora.

Aquí vemos la diferencia importante que nos ofrece Villaurrutia sobre la homosexualidad mexicana. La diferencia en la identidad de género de los amantes homosexuales (o sea, la

\footnotetext{
1.3 Esta imagen hace eco de dos otros poemas que se tratan del deseo nocturnal, "Nocturno eterno": cuando los ojos cierran sus ventanas" y "Cuando la tarde ...": "Cuando la tarde cierra sus ventanas remotas" (Obras 51-52 y 61-62).
} 
necesidad, según Paz, que uno de ellos desempeñe el rol masculino, y el otro el femenino) no importa. La diferencia toma otra forma aquí: la diferencia racial - cosa que no figuraba en el modelo homosexual de Paz (a pesar de ser una clave a sus modelos de heterosexualidad mexicana), pero que figuraba esencialmente en el modelo de Vasconcelos. Sin embargo, como no hay mestizaje, la utopía eugenésica de la raza cósmica no tiene que ver, ni tampoco las relaciones jerárquicas que determinan la mexicanidad para Paz. El hecho de que la identidad propia del homosexual se desvanece con el amante rubio o negro implica que las jerarquías de raza tampoco se mantienen (para él).

El deseo mexicano homosexual villaurrutiano permite la diferencia racial, e implica la posibilidad de cualquier tipo de diferencia, aun la diferencia de género (en "Nocturno de la estatua", el narrador encuentra en el espejo una estatua a quien acaricia "como una hermana imprevista"). Pero lo que ocurre en Villaurrutia es que la diferencia se borra a través del acto sexual. El enigma compartido de los homosexuales requiere que todos se escondan; comparten también la diferencia de su sexualidad. La diferencia no es tan amenazadora para ellos porque viven la diferencia perpetuamente en sus deseos. Se podría leer el narcisismo villaurrutiano como el deseo por uno mismo encontrado en el otro, en un reflejo mutuo de seres diferentes.

Mi intención no ha sido llenar un hueco en el esquema definitivo de la sexualidad mexicana. Tampoco quiero negar el valor simbólico de los diferentes tropos del deseo en México. Particularmente, el modelo de Paz de la homosexualidad ha sido empleado efectivamente para combatir la noción de que los paradigmas de la homosexualidad de los Estados Unidos o de otras culturas dominantes sean universales. Los investigadores de la sociología en México que han estudiado el género y la sexualidad han demostrado la validez del modelo y la necesidad de cuestionar presuposiciones totalizadoras de todo tipo. La lección que nos da Villaurrutia (algo que aparentemente ha escapado a estos sociólogos en muchas ocasiones) es que el caso de México tampoco es monolítico. El deseo homosexual que se halla en los escritos de Villaurrutia, con o sin la marca de raza, puede ser representativo de la homosexualidad mexicana, o de un segmento del mundo homosexual mexicano, o meramente una expresión muy personal e individual. Lo que deberíamos sacar de Villaurrutia es la necesidad de evitar que los tropos existentes del deseo, de la identidad, y del comportamiento sexuales, sean universales o nacionales, se entiendan como reglas totalizadoras.

\section{Bibliografía}

Aramoni, Aniceto. Psicoanálisis de la dinámica de un pueblo. México: UNAM, 1961. Azuela, Mariano. Los de abajo [1916]. México: Fondo de Cultura Económica, 1993. Bartra, Roger. La jaula de la melancolía. México: Grijalbo, 1987. Campo, Ángel de. Ocios y apuntes y La Rumba [1890]. México: Porrúa, 1981. Campos, Rubén M. El folklore literario de México. México: Secretaría de Educación Pública/Talleres Gráficos de la Nación, 1929.

Carrier, Joseph. De los otros: Intimacy and Homosexuality Among Mexican Men. Nueva York: Columbia University Press, 1995. 
Castellanos, Rosario. "Discriminación en Estados Unidos y en Chiapas". El uso de la palabra. México: Excélsior-Crónicas, 1974. 139-42.

Cocteau, Jean. The White Book/Le livre blanc [1928]. M. Crosland, trad. San Francisco: City Lights Books, 1989.

Cruz, Sor Juana Inés de la. Obras completas. 8ª Ed. México: Porrúa, 1992.

Cuesta, Jorge. Poesía y crítica. México: Consejo Nacional para la Cultura y las Artes, 1991.

Fernández de Lizardi, José Joaquín. La Quijotita y su prima [1818/1831]. México: Porrúa, 1990.

Freud, Sigmund. "On Narcissism: An Introduction" [1914]. The Standard Edition of the Complete Psychological Works of Sigmund Freud. J. Strachey, ed. Londres: The Hogarth Press and the Institute of Psychoanalysis, 1957. 73-102.

Fuentes, Carlos. Zona sagrada [1967]. México: Siglo Veintiuno, 1988.

Gamboa, Federico. Santa [1902]. México: Grijalbo, 1979.

Gide, André. Corydon [1924]. J. Gómez de la Serna, trad. Madrid: Alianza, 1971. L'immoraliste. París: Mercure de France, c1902.

Si le grain ne meurt [1955]. París: Gallimard, 1993.

Goldwert, Marvin. Machismo and Conquest: The Case of Mexico. Lanham, MD: University Press of America, 1983.

González Obregón, Luis. México viejo 1521-1821. México: Patria, 1945.

Issorel, Jacques, Comp. y Trad. "Neuf Interviews de Xavier Villaurrutia". Intellectuels et état au Méxique au XX siècle. GRAL Institut d'Études Mexicaines-Perpignan, ed. París: CNRS, 1979. 113-124.

Mirandé, Alfredo. Hombres y machos: Masculinity and Latino Culture. Boulder, CO: Westview Press, 1997.

Monsiváis, Carlos. Amor perdido [1977]. México: Era, 1990. "Notas sobre la cultura mexicana en el siglo veinte". Historia general de México, II. D. Cosío Villegas, ed. México: El Colegio de México, 1976. 1377-1548. "Ortodoxia y heterodoxia en las alcobas". Debate feminista 6/11 (abril de 1995): 183-212.

La mujer del puerto. Dir. Arcady Boytler. México: Eurindia, 1933

Murray, Stephen O. Latin American Male Homosexualities. Albuquerque: University of New Mexico, 1995.

Nervo, Amado. El donador de almas [1904]. México: B. Costa-Amic, 1976.

Paredes, Américo. Estados Unidos, México y el machismo [1967]. Austin: University of Texas Institute of Latin American Studies Offprint Series, s.f.

Paz, Octavio. El laberinto de la soledad [1972]. México: Fondo de Cultura Económica, 1989.

Xavier Villaurrutia en persona y en obra. México: Fondo de Cultura Económica, 1978.

Ramírez, Santiago. El mexicano: Psicologia de sus motivaciones. México: Pax-México, 1959.

Ramos, Samuel. El perfil del hombre y la cultura en México [1934]. México: EspasaCalpe, 1997.

Rojas González, Francisco. La negra Angustias [1948]. México: Fondo de Cultura Económica, 1984. 
Sheridan, Guillermo. Los Contemporáneos ayer [1985]. México: Fondo de Cultura Económica, 1993.

"Villaurrutia habla dos veces". Vuelta (5/95): 58-59.

Vasconcelos, José. La flama: Los de arriba en la Revolución, historia y tragedia. México: Continental, 1959

La raza cósmica [1925]. México: Espasa-Calpe, 1986. Ulises criollo [1936-39]. 4 Vols. México: Fondo de Cultura Económica, 1984.

Villaurrutia, Xavier. Cartas de Xavier Villaurrutia a Salvador Novo [1935-1936]. México: Instituto Nacional de Bellas Artes, 1966. Nocturno de los ángeles [1936]. Edición facsimilar de la primera edición y del manuscrito. México: Equilibrista, 1987. Nostalgia de la muerte [1938]. México: Premia, 1990. Obras [1966]. México: Fondo de Cultura Económica, 1991. 